capillaris, as well as the remaining immunological response.

The ocular disease of our patient had a remarkable similarity to syphilitic neuroretinitis described by Duke-Elder as retinitis circumpapillaris. ${ }^{8}$ Smith $e t a l^{9}$ has proposed previously that rare unilateral RP may in fact often have represented seronegative syphilis. Since late syphilis is extremely rare in Finland, it is an unlikely cause of our patient's disease. On the other hand, LB is endemic in the southwest archipelago of Finland and the number of new cases is also increasing in the southern parts of the mainland, from where our patient came.

We agree with MacDonald ${ }^{10}$ and others ${ }^{611}$ about the fact that serological testing for LB is ambiguous. Furthermore, Isogai and coworkers recently found Borrelia antibodies in a significant number of patients with non-infectious uveitis entities. ${ }^{12}$ Our case stresses the need for sophisticated methods to detect borrelial structures within the eye. The high sensitivity and specificity of the PCR method makes it one of the most promising candidates among the technological inovations in the diagnosis of borrelial and other microbial infections.

The early diagnosis of ocular borreliosis is of utmost importance. Elimination of $B$ burgdorferi from the eye at the early stages of infection may prevent the development of irreversible damages and possibly also the triggering of the autoimmune process.

1 Baum J, Barza M, Weinstein P, Groden J, Aswad M. Bilateral keratitis as a manifestation of Lyme disease. Am $\mathcal{F}$ Ophthalmol 1988; 105: 75-7.

2 Winward KE Smith JL, Culbertson WW, Paris-Hamelin A. Ocular Lyme borreliosis. Am f Ophthalmol 1989; 108: 6517 .

3 Bialasiewicz AA, Huk W, Druschky KF, Naumann GOH. Borrelia burgdorferi-Infektion mit beidseitiger Neuritis nervi optici und intrazerebralen Demyelinisierungsherden. Klin Monatsbl A ugenheilkd 1989; 195: 91-4.

4 Smith JL, Winward KE, Nicholson DF, Albert DW. Retinal vasculitis in Lyme borreliosis. $\mathcal{F}$ Clin Neuro Ophthalmol 1991; 11 : 7-15.

5 Schechter SL. Lyme disease associated with optic neuropathy. $A m$ F Med 1986; 81: 143-5.

6 Hedberg CW, Osterholm MT, MacDonald KL, White KE. An interlaboratory study of antibody to Borrelia burgdorferi. An interlaboratory study of antib

7 Wallich R, Moter SE, Simon MM, Ebnet K, Heiberger A, Kramer MD. The Borrelia burgdorferi flagellum-associated 41-kilodalton antigen (flagellin) - molecular cloning, expression, and amplification of the gene. Infect Immun 1990; 58: 1711-9.

8 Duke-Elder S, Dobree JH. Diseases of the retina. In: DukeElder S, ed. System of ophthalmology, Vol X. London: Kimpton, 1967: 252-62.

9 Smith J-L, Singer JA, Moore MD Jr, Yobs AR. Seronegative ocular and neurosyphilis. Am $\mathcal{F}$ Ophthalmol 1965; 59: 75363.

10 MacDonald AB. Ambiguous serologies in active Lyme borreliosis. $\mathcal{F}$ Clin Neuro Ophthálmol 1988; 8: 79-80.

11 Winward KE, Smith JL. Ocular disease in Caribbean patients with serologic evidence of Lyme borreliosis. $\mathcal{F}$ Clin Neuro Ophthalmol 1989; 9: 65-70

12 Isogai $\mathrm{E}$, Isogai $\mathrm{H}$, Kotake $\mathrm{S}$, Yoshikawa $\mathrm{K}$, Ichiishi $\mathrm{A}$, Kosaka S, et al. Detection of antibodies against Borrelia burgdorferi in patients with uveitis. Am $\mathcal{F}$ Ophthalmol 1991; 112: 23-30.

\title{
Two cases of coloboma associated with unbalanced translocations
}

\author{
Michael Goggin, Michael O'Keefe, Helen Hughes
}

\begin{abstract}
Two cases of coloboma are recorded, both secondary to previously unreported unbalanced translocations. These cases underline the association of chromosomal abnormalities and coloboma, particularly when accompanied by systemic abnormalities. They also highlight the importance of a full systemic assessment of coloboma patients and adequate genetic counselling for both patients and their families. (BrF Ophthalmol 1993; 77: 122-123)
\end{abstract}

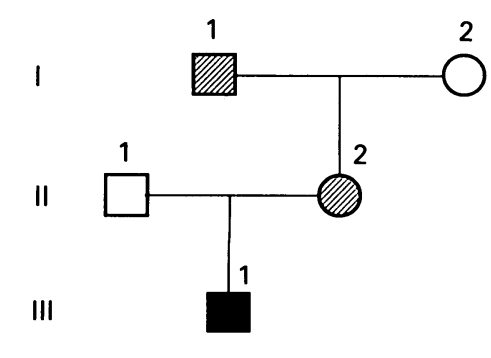

Family 1

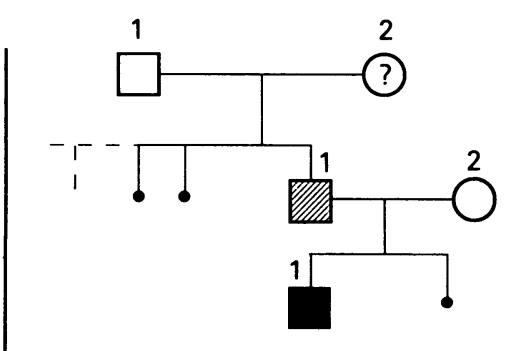

Family 2
Hereditary coloboma is described as an isolated defect often inherited as an autosomal dominant trait $^{12}$ and, less commonly, in an autosomal recessive manner. ${ }^{34}$ An $\mathrm{X}$-linked recessive pattern has also been described. ${ }^{5} \mathrm{It}$ is a feature of many syndromes, including various chromosomal disorders. These have been the subject of exhaustive reviews. ${ }^{26} \mathrm{We}$ report two patients with coloboma/microphthalmos related to unbalanced translocations not previously described in the literature.

\section{Case reports}

CASE 1

A male only child of a phenotypically normal father and mother presented at 4 months with bilateral severe ptosis occluding the visual axes (Fig 1, family 1, III-1). Both eyes were microphthalmic with colobomas of the iris, retina/choroid, macula, and disc. The child was also found to have a duplex renal system, cerebral atrophy, and developmental delay.

Bilateral frontalis sling ptosis procedures were carried out, and the fixation pattern has shown a steady improvement since then.

Chromosomal analysis revealed a 5-14 
Department of

Paediatric

Ophthalmology, The

Children's Hospital,

Temple Street, Dublin 1,

Republic of Ireland

$M$ Goggin

M O'Keefe

Institute of Medical

Genetics, University of

Wales, Heath Park,

Cardiff CF4 4XW, UK

H Hughes

Correspondence to:

Michael Goggin, Department

of Ophthalmology, Mater

Private Hospital, Eccles

Street, Dublin 7, Ireland.

Accepted for publication

17 September 1992 unbalanced translocation in the boy and a balanced translocation between chromosomes 5 and 14 in the mother (Fig 1, family 1, II-2). His karyotype is $46, \mathrm{XY}, \operatorname{der}(14), \mathrm{t}(5 ; 14)(\mathrm{pl} 14 ; \mathrm{q} 32 \cdot 3)$ mat. The apparent duplication of the distal portion of the short (p) arm of chromosome 5 and the deletion of the terminal end of the long (q) arm of chromosome 14 is a result of inheriting a maternal chromosome 14, the long (q) arm of which was involved in a reciprocal translocation with the short (p) arm of chromosome 5. The mother's karyotype (which differed only in the sex chromosome composition from her father's (Fig 1 , family $1, \mathrm{I}-1)$ ) is $46, \mathrm{XX}, \mathrm{t}(5 ; 14)(\mathrm{p} 14$; q32·3)).

CASE 2

The only child (male) of phenotypically normal parents presented with bilateral extensive colobomas affecting the iris, choroid, and retina, including the macular area and the optic discs (Fig 1, family 2, III-1). This was more extensive in the left eye. His fixation pattern was central, steady but unmaintained on the right and central, unsteady and unmaintained on the left. Furthermore, he had dysmorphic features, with a small head, nasal bone aplasia, short neck, mental handicap, and developmental delay.

The child's karyotype is $46, \mathrm{XY}, \operatorname{der}(8), \mathrm{t}(4 ; 8)$ (p12;p23)pat. There is an apparent duplication of most of the short (p) arm of chromosome 4 and a deletion of a small terminal portion of the short (p) arm of chromosome 8. This is the result of inheriting a paternal chromosome 8 , of which the terminal section of the short (p) arm was involved in a reciprocal translocation with most of the short (p) arm of chromosome 4. The father's karyotype is $46, \mathrm{XY}, \mathrm{t}(4 ; 8)(\mathrm{p} 12 ; \mathrm{p} 23)$ (Fig 1, family 2, II-1).

Significantly, the paternal grandmother (Fig 1, family 2, I-2) had a history of several miscarriages. Details of her karyotype and her obstetric history are not available because she lives in another European country. The mother of our patient has also had a miscarriage subsequent to genetic counselling.

\section{Comment}

Coloboma/microphthalmos is a relatively frequently occurring ophthalmic defect. Most cases are of isolated ophthalmic defects unrelated to other birth defects. Karyotypes are normal and first degree relatives are clinically normal. An autosomal dominant inheritance pattern for this condition has been well recognised for some time, ${ }^{1}$ and an autosomal recessive pattern has been suggested in some cases. ${ }^{34}$ The condition is also described in conjunction with several chromosomal disorders, ${ }^{2}$ including a deletion of the retinoblastoma gene at $13 \mathrm{q} 14 .{ }^{7}$ Presumably, the closure of the optic fissure is a complex process which involves multiple genes. The finding of a coloboma should alert the physician to the possibility of chromosomal disease and the systemic complications this implies. ${ }^{8}$

Some unbalanced translocations in the fetus are not compatible with life and may be associated with an increased risk of spontaneous abortion.

We describe two cases associated with specific chromosomal disorders. The first involves an unbalanced translocation between chromosomes 5 and 14 resulting in duplication of the distal portion of $5 p$ and deletion of the terminal end of 14q. The second involves an unbalanced translocation between chromosomes 4 and 8 causing $4 \mathrm{p}$ trisomy and deletion of a terminal portion of $8 \mathrm{p}$. The former also had severe ptosis and both had significant systemic abnormalities such as would be expected with these kinds of chromosomal abnormalities.

Following a literature search we believe this to be the first report of the association of these translocations with coloboma/microphthalmos. A review of 27 cases of trisomy $4 p^{9}$ showed one case with unilateral coloboma and several other ophthalmic abnormalities including strabismus, pigmentary retinopathy, optic nerve hypoplasia, nystagmus, antimongoloid slanting, and microphthalmia. In most of the families a parent carrieda balanced translocation. However, none involved chromosome 8 (see case 2 ).

The associations listed above highlight the necessity for both a full ophthalmic examination of the first degree relatives of all patients with coloboma and a routine paediatric assessment, including a karyotype, of the patients themselves. We advise that the parents of coloboma patients receive adequate genetic counselling if there is a family history of coloboma or an abnormal karyotype.

1 Duke-Elder S. Congenital deformities of the eye: 1. Anomalies in organogenesis. In: Duke-Elder S, ed. System of ophthal mology, vol III, part 2, Congenital deformities. London: Kology, vol III, part

2 Pagon R. Ocular coloboma. Surv Ophthalmol 1981; 25: 223-36. Francois J. Colobomatous malformations of the ocular globe. Int Ophthalmol Clin 1968; 8: 797-816.

4 McMillan L. Anophthalmos and maldevelopment of the eyes four cases in the same family. Brf Ophthalmol 1921;5:121-2.

5 Goldberg MF, McKusick VA. X-linked colobomatous microphthalmos and other congenital anomalies. $A m \mathcal{F}$ Ophthalmol 1971; 71: 1128-33.

6 Warburg $M$. Diagnostic precision in microphthalmos and coloboma of heterogeneous origin. Birth Defects 1982; 18: 31 50.

7 Wilson WG, Campochiaro PA, Conway BP. Deletion (13)(q14.1q14.3) in two generations: variability of ocular manifestations and definition of the phenotype. Am $\mathcal{F} \mathrm{Med}$ Genet 1987; 28:675-83.

8 Taylor DSI. The genetic implications of optic disc anomalies. Trans Ophthalmol Soc UK 1985; 104: 853-6.

9 Gonzalez CH, Sommer A, Meisner LF, Elejalde BR, Opitz JM. The trisomy $4 \mathrm{p}$ syndrome: case report and review. $A m \mathcal{F}$. Genet 1977; 1: 137-56. 